\title{
Etiologia e resistência de isolados bacterianos de hemoculturas da Sala de Cuidados Intermediários de um Hospital Universitário em Pernambuco
}

\author{
Etiology and resistance of bacterial isolates from blood cultures in the Intermediate Care Room of \\ a University Hospital in Pernambuco \\ Etiología y resistencia de aislados bacterianos de hemocultivos en la Sala de Cuidados Intermedios \\ de un Hospital Universitario de Pernambuco
}

\section{Resumo}

Descrever a etiologia e a resistência dos isolados bacterianos das hemoculturas de pacientes internados na Sala de Cuidados Intermediários do Hospital Universitário do Vale do São Francisco, Petrolina/PE. Foram analisadas, retrospectivamente, todas as hemoculturas, realizadas pelo Laboratório de Análises Clínicas do Hospital Universitário, entre janeiro a dezembro de 2020 de pacientes internados na Sala de Cuidados Intermediários através da análise descritiva e quantitativa. Os dados foram tabulados em planilhas do Excel@ e foi realizada análise dos valores absolutos e percentuais. As identificações das bactérias e os antibiogramas foram realizadas através do sistema automatizado BD Phoenix TM, de acordo com a metodologia do Clinical and Laboratory Standards Institute de 2020. Foram coletadas 113 hemoculturas, sendo 29 positivas (26\%) para crescimento bacteriano. As bactérias mais prevalentes foram Staphylococcus coagulase negativa (45\%), Escherichia coli (17\%) e Staphylococcus aureus (10\%). As bactérias Staphylococcus spp apresentaram resistência à ampicilina e penicilina, enquanto as Klebsiella pneumoniae e Acinetobacter baumannii demonstraram importante resistência aos carbapenêmicos e às cefalosporinas. Houve o predomínio das bactérias gram-positivas e 55\% das bactérias foram Staphylococcus spp, sendo que todas essas apresentaram resistência a ampicilina e penicilina. Além disso, observou-se resistência por parte $d o$. pneumoniae e A. baumannii aos carbapenêmicos e às cefalosporinas. Através do estudo do perfil microbiológico das bactérias relacionadas às infecções hospitalares é possível construir protocolos de antibioticoterapia empírica adequados, assim como a elaboração e implementação de medidas preventivas e de controle dessas infecções.

Palavras-chave: Bacteremia; Infecção hospitalar; Resistência bacteriana a antibióticos; Microbiologia; Hospitais universitários.

\section{Abstract}

Describe the etiology and resistance of bacterial isolates from blood cultures of patients admitted to the Intermediate Care Room of the University Hospital of Vale do São Francisco, Petrolina / PE. All blood cultures, performed by the 
Clinical Analysis Laboratory of the University Hospital, between January and December 2020 of patients admitted to the Intermediate Care Room through retrospective and quantitative analysis were retrospectively analyzed. The data were tabulated in Excel ${ }^{\circledR}$ spreadsheets and an analysis of absolute and percentage values was performed. The identification of bacteria and antibiograms were performed using the automated BD Phoenix TM system, according to the methodology of the Clinical and Laboratory Standards Institute of 2020. 113 blood cultures were collected, 29 of which were positive $(26 \%)$ for bacterial growth. The most prevalent bacteria were coagulase negative Staphylococcus (45\%), Escherichia coli (17\%) and Staphylococcus aureus (10\%). Staphylococcus spp bacteria showed resistance to ampicillin and penicillin, while Klebsiella pneumoniae and Acinetobacter baumannii showed important resistance to carbapenems and cephalosporins. There was a predominance of gram-positive bacteria and 55\% of the bacteria were Staphylococcus spp, all of which showed resistance to ampicillin and penicillin. In addition, there was resistance from K. pneumoniae and A. baumannii to carbapenems and cephalosporins. Through the study of the microbiological profile of bacteria related to nosocomial infections, it is possible to build adequate empirical antibiotic therapy protocols, as well as the design and implementation of preventive and control measures for these infections.

Keywords: Bacteremia; Cross infection; Drug resistance, Bacterial; Microbiology; University's hospital.

\section{Resumen}

Describir la etiología y resistencia de aislamientos bacterianos de hemocultivos de pacientes ingresados en la Sala de Cuidados Intermedios del Hospital Universitario Vale do São Francisco, Petrolina / PE. Se analizaron retrospectivamente todos los hemocultivos, realizados por el Laboratorio de Análisis Clínicos del Hospital Universitario, entre enero y diciembre de 2020 de los pacientes ingresados en la Sala de Cuidados Intermedios mediante análisis retrospectivo y cuantitativo. Los datos se tabularon en hojas de cálculo Excel@ y se realizó un análisis de valores absolutos y porcentuales. La identificación de bacterias y antibiogramas se realizaron mediante el sistema automatizado BD Phoenix TM, según la metodología del Clinical and Laboratory Standards Institute de 2020. Se recolectaron 113 hemocultivos, 29 de los cuales fueron positivos (26\%) para crecimiento bacteriano. Las bacterias más prevalentes fueron Staphylococcus coagulasa negativo (45\%), Escherichia coli (17\%) y Staphylococcus aureus (10\%). Las bacterias Staphylococcus spp mostraron resistencia a ampicilina y penicilina, mientras que Klebsiella pneumoniae y Acinetobacter baumannii mostraron resistencia importante a carbapenémicos y cefalosporinas. Hubo predominio de bacterias grampositivas y el 55\% de las bacterias fueron Staphylococcus spp, todas las cuales mostraron resistencia a ampicilina y penicilina. Además, hubo resistencia de $K$. pneumoniae y A. baumannii a carbapenémicos y cefalosporinas. A través del estudio del perfil microbiológico de bacterias relacionadas con infecciones nosocomiales, es posible construir protocolos empíricos adecuados de terapia antibiótica, así como el diseño e implementación de medidas preventivas y de control de estas infecciones.

Palabras clave: Bacteriemia; Infección hospitalaria; Farmacorresistencia bacteriana; Microbiología; Hospitales universitarios.

\section{Introdução}

As Infecções Relacionadas à Assistência em Saúde (IRAS) são infecções causadas por fungos, vírus e bactérias e são adquiridas durante a assistência em saúde em qualquer ambiente, abrangendo atendimentos ambulatoriais, hospitalares ou domiciliares e podendo estar relacionadas com procedimentos assistenciais diagnósticos ou terapêuticos (Center for Disease Control and Prevention, 2019).

Os fatores que contribuem para essas infecções estão relacionados aos erros de antissepsia e esterilização dos materiais; procedimentos incorretos; procedimentos invasivos; grande circulação de pessoas no ambiente hospitalar; uso incorreto dos antimicrobianos; não higienização correta das mãos; doenças crônicas degenerativas e à idade do paciente (dos Santos et al., 2014).

Segundo a Agência Nacional de Vigilância Sanitária (ANVISA) são IRAS as infecções de trato urinário (ITU) associadas a cateter, as pneumonias associadas a ventilação, as infecções da corrente sanguínea associadas a acesso central e infecções cirúrgicas (Agência Nacional de Vigilância Sanitária, 2017).

A presença de microrganismos na corrente sanguínea pode ocorrer através da bacteremia, que corresponde a presença de bactérias na corrente sanguínea, podendo ser de origem primária, quando há entrada direta desses patógenos na corrente sanguínea através de procedimentos invasivos, como agulha ou cateter; ou de origem secundária, quando ocorre a partir de um foco primário, através de disseminação linfática ou hematogênica (Oplustil, 2010). Sendo assim, o desenvolvimento da bacteremia pode vir a causar a sepse, síndrome de resposta inflamatória sistêmica com disfunção orgânica, desencadeada por 
uma reação inadequada à infeç̧̃ão. No Brasil, um estudo realizado com 227 Unidades de Terapia Intensiva (UTIs), demonstrou que as infecções de corrente sanguínea são responsáveis por 30\% da ocupação dos leitos e possuem 55\% de letalidade, enquanto a média mundial é de 30 a 40\% (Machado et al., 2017). Para a identificação dos microrganismos na corrente sanguínea é indicado a realização da hemocultura, exame considerado padrão-ouro (Miller et al., 2018), possibilitando, assim, melhor conduta terapêutica.

Em um estudo sobre as IRAS em unidades de terapia intensiva no Brasil, demonstrou-se que os microrganismos mais prevalentes são Staphylococcus coagulase-negativa, Pseudomonas aeruginosa e Staphylococcus aureus (Gomes et al., 2020). Observou-se em revisão integrativa que os antibióticos de maior resistência bacteriana são piperacilina + tazobactam, ceftriaxona, ceftazidima, cefotaxima, cefepime, imipenem e meropenem para Escherichia coli e Klebsiella pneumoniae; ampicilina e vancomicina para Enterococcus faecium; oxacilina para Staphylococcus aureus; ciprofloxacina, ceftriaxona e imipenem para Acinetobacter baumannii e Pseudomonas aeruginosa; ampicilina, ceftriaxona e ciprofloxacina para Enterobacteriaceae em UTIs e em outras áreas de hospitalização (Rodrigues et al., 2018).

Tem-se observado um crescente aumento da resistência bacteriana aos antimicrobianos, gerando dificuldades no controle de infecções e aumento nos custos em saúde. Esses patógenos resistentes causam cerca de 700.000 mortes por ano em todo o mundo, podendo chegar a atingir 10 milhões de mortes até 2050 se nenhuma medida for tomada (World Health Organization, 2019)

A Unidade de Cuidados Intermediários (UCI) é destinada a usuários em situação clínica de risco moderado ou semicríticos, que necessitam de monitorização contínua e cuidados semi-intensivos, além de equipamentos e equipe multiprofissional especializada. Pacientes internados nessas unidades se submetem a diversos tipos de procedimentos invasivos, ficando susceptíveis à entrada de patógenos e, consequentemente, às IRAS.

Dessa forma, o estudo etiológico e a caracterização de sensibilidade e resistência aos antimicrobianos é essencial para a construção de protocolos em saúde que possibilitem o manejo adequado das infecções, evitando a oneração dos serviços de saúde e o prolongamento do tempo de tratamento dos pacientes e, assim como melhor controle das bactérias resistentes (Freitas et al., 2017).

Em razão disso, o presente estudo tem como objetivo analisar retrospectivamente a etiologia e a resistência aos antimicrobianos de amostras de hemoculturas da Sala de Cuidados Intermediários do Hospital Universitário de Petrolina.

\section{Metodologia}

No presente estudo foi utilizada metodologia de natureza quantitativa (Pereira et al., 2018). Trata-se de um estudo observacional e retrospectivo cujo dados foram coletados por meio de impressos laboratoriais do próprio serviço.

Foram avaliados os laudos das hemoculturas de pacientes internados na Sala de Cuidados Intermediários, no período de janeiro a dezembro de 2020, do Hospital Universitário da Universidade Federal do Vale do São Francisco (HUUNIVASF/EBSERH) de Petrolina, localizado no estado de Pernambuco.

O hospital possui perfil assistencial de hospital geral de média a alta complexidade ao público adulto da região, sendo referência em saúde para a VIII Gerência Regional de Saúde (GERES) de Pernambuco. Dessa forma, o hospital comporta os municípios de Afrânio, Cabrobó, Dormentes, Lagoa Grande, Orocó, Petrolina e Santa Maria da Boa Vista; o que corresponde a uma população de 475.740 habitantes (Secretaria Estadual de Saúde de Pernambuco, 2020).

Os dados foram tabulados na planilha do Microsoft Office Excel®, sendo divididos em amostras positivas e negativas, e realizada análise descritiva com valores absolutos e em percentuais. Foram consideradas positivas todas as hemoculturas com qualquer crescimento bacteriano em um dos quatro frascos coletados por paciente. Foram analisadas as variáveis ocorrência de bactérias e o perfil de sensibilidade e resistência aos antibióticos testados. A partir disso, foi construído tabelas e gráficos para 
análise e demonstração dos resultados.

As hemoculturas foram processadas no setor de microbiologia do hospital a partir da utilização do sistema automatizado PHOENIX, da BD, utilizando-se os painéis adequados. Os resultados foram classificados em sensível (S) e resistente (R), de acordo com a metodologia do Clinical and Laboratory Standards Institute (2018).

O trabalho foi submetido ao Comitê de Ética da Universidade Federal Rural de Pernambuco (UFRPE), sendo aprovado através do CAAE: 40360120.4.0000.9547.

\section{Resultados}

Dentre as 113 hemoculturas realizadas, 29 foram positivas para crescimento bacteriano (26\%) e 84 foram negativas (74\%). Em relação aos agentes etiológicos foram confirmadas 8 espécies bacterianas, a saber: Staphylococcus coagulase negativa, Escherichia coli, Staphylococcus aureus, Acinetobacter baumannii, Klebsiella pneumoniae, Klebsiella aerogenes, Enterococcus faecalis e Enterobacter clocae. Pode-se observar no gráfico 1 que as principais espécies identificadas foram Staphylococcus coagulase negativa (45\%), Escherichia coli (17\%) e Staphylococcus aureus (10\%). As demais bactérias encontradas resultaram em $27 \%$ dos isolados bacterianos.

Gráfico 1. Agentes etiológicos isolados em hemoculturas de pacientes internados na SCI do HU-UNIVASF (EBSERH), no período de janeiro a dezembro de 2020.

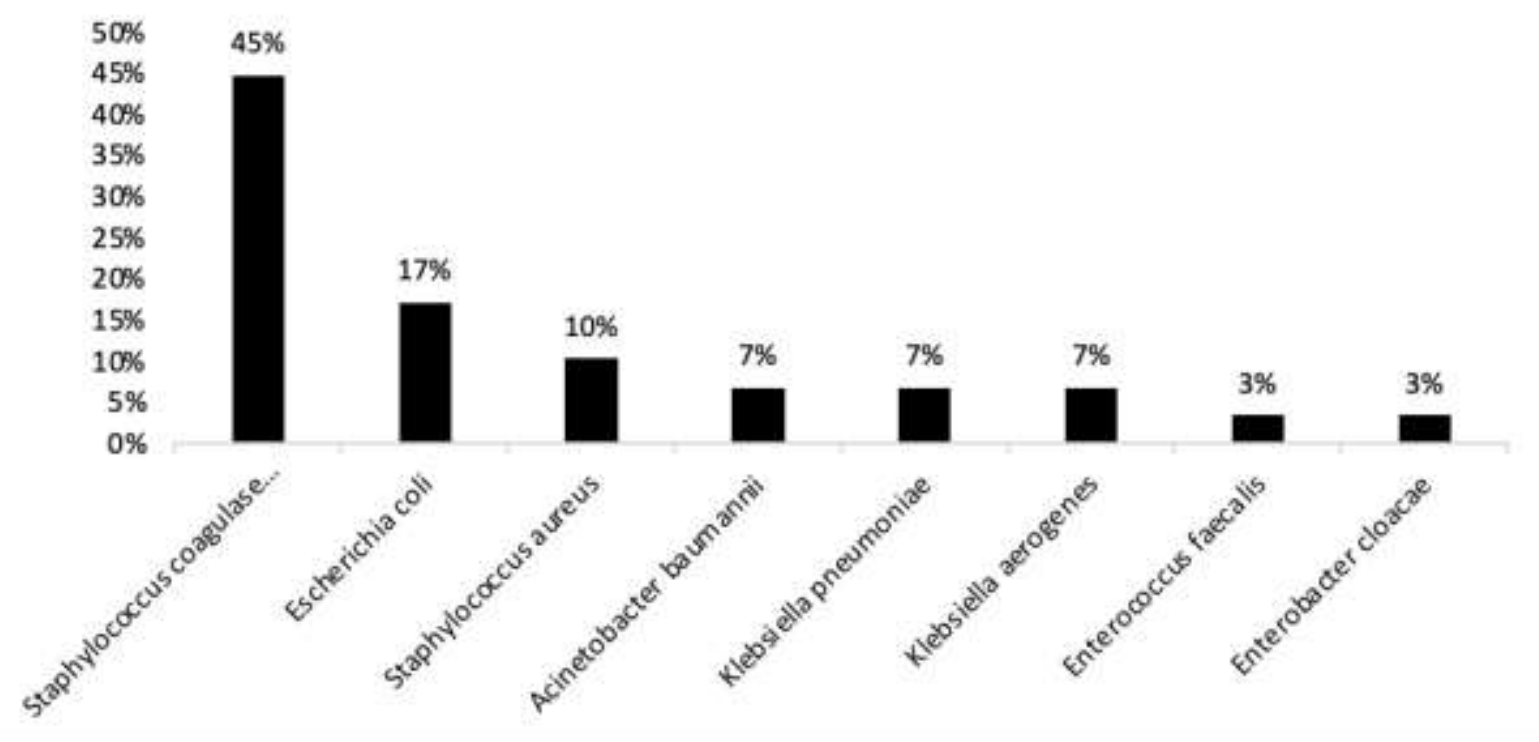

Fonte: Autores.

Em relação a resistência dos isolados bacterianos gram positivos, o perfil de Staphylococcus coaguase negativa (SCN), encontrado nas hemoculturas, foi de $100 \%$ de resistência a ampicilina, norfloxacino e penicilina; foram observados outros padrões de resistência para clindamicina (85\%), eritromicina (85\%), oxacilina (85\%), rifampicina (46\%), sulfametoxazol + trimetoprima $(77 \%)$ e todos os casos foram $100 \%$ sensíveis a daptomicina, linezolide, minociclina e vancomicina (tabela 1$)$.

Nos isolados de Staphylococcus aureus, observou-se (tabela 1) resistências variáveis a clindamicina (67\%) e 100\% de sensibilidade a oxacilina, sulfametoxazol + trimetoprima e vancomicina.

Quanto ao Enterococcus faecalis, encontrou-se (tabela 1) 100\% de resistência apenas a ceftarolina e $100 \%$ de sensibilidade a ampicilina, daptomicina, linezolide, penicilina, tigeciclina e vancomicina. 
Tabela 1. Perfil de resistência das bactérias gram positivas isoladas de hemoculturas coletadas em pacientes internados na SCI do HU-UNIVASF (EBSERH), no período de janeiro a dezembro de 2020.

\begin{tabular}{ll}
\hline Antimicronianos & Espécies bacterianas \\
\hline
\end{tabular}
$S$. coagulase negativa
S. aureus
E. faecalis

\begin{tabular}{|c|c|c|c|c|c|c|}
\hline & $\mathrm{n}$ & $\%$ & $\mathrm{n}$ & $\%$ & $\mathrm{n}$ & $\%$ \\
\hline Ampicilina & 13 & 100 & 3 & 100 & 1 & 0 \\
\hline Ceftarolina & NT & NT & 3 & 0 & 1 & 100 \\
\hline Clindamicina & 13 & 85 & 3 & 67 & NT & NT \\
\hline Daptomicina & 13 & 0 & 3 & 0 & 1 & 0 \\
\hline Eritromicina & 13 & 85 & 3 & 67 & NT & NT \\
\hline Linedolide & 13 & 0 & 3 & 0 & 1 & 0 \\
\hline Minociclina & 13 & 0 & 3 & 0 & NT & NT \\
\hline Norfloxacino & 6 & 100 & NT & NT & NT & NT \\
\hline Oxacilina & 7 & 85 & 3 & 0 & NT & NT \\
\hline Penicilina & 13 & 100 & 3 & 100 & 1 & 0 \\
\hline Rifampicina & 13 & 46 & 3 & 0 & NT & NT \\
\hline Smt+tmp & 13 & 77 & 3 & 0 & NT & NT \\
\hline Tigeciclina & NT & NT & 3 & 0 & 1 & 0 \\
\hline Vancomicina & 13 & 0 & 3 & 0 & 1 & 0 \\
\hline
\end{tabular}

Legenda: NT: não testado; n: número de isolados bacterianos; \%: percentual de resistência; smt+tmp: sulfametoxazol + trimetoprima. Fonte: Autores.

Quanto às bactérias gram negativas isoladas, foram encontrados 2 casos de Acinetobacter baumannii, 5 casos de Escherichia coli, 1 caso de Enterobacter cloacae, 2 casos de Klebsiella aerogenes e 2 casos de Klebsiella pneumoniae.

O perfil de resistência observado para Acinetobacter baumannii foi de $100 \%$ de resistência a imipinem e meropenem e $100 \%$ de sensibilidade a ampicilina + sulbactam (tabela 2 ).

A Escherichia coli apresentou $100 \%$ de resistência a ampicilina, ampicilina + sulbactam, cefepime e sulfametoxazol + trimetoprima; $80 \%$ de resistência a ceftriaxona e sensibilidade completa a amicacina, cefoxtina, ertapenem gentamicina, imipinem meropenem, piperacilina + tazobactam e tigeciclina (tabela 2).

Nos casos de Enterobacter cloacae, foi observado $100 \%$ de resistência a ampicilina, ampicilina + sulbactam, cefazolina, cefepime, cefoxtina, ceftriaxona, ertapenem, piperacilina + tazobactam e tigeciclina e $100 \%$ de sensibilidade a amicacina, ciprofloxacino, gentamicina, imipinem e meropenem (tabela 2).

A Klebsiella aerogenes demonstrou $100 \%$ de sensibilidade a amicacina, imipinem e meropenem (tabela 2). Foi observado índice intermediário à piperacilina + tazobactam.

A Klebsiella pneumoniae apresentou $100 \%$ de resistência a meropenem, piperacilina + tazobactam e a sensibilidade 
foi de $100 \%$ a amicacina e imipinem (tabela 2).

Tabela 2. Perfil de resistência das bactérias Gram negativas isoladas de hemoculturas coletadas em pacientes internados na SCI do HU-UNIVASF (EBSERH), no período de janeiro a dezembro de 2020.
A. baumannii
E. coli
E. cloacae
K. aerogenes
K.pneumoniae

\begin{tabular}{|c|c|c|c|c|c|c|c|c|c|c|}
\hline & $\mathrm{n}$ & $\%$ & $\mathrm{n}$ & $\%$ & $\mathrm{n}$ & $\%$ & $\mathrm{n}$ & $\%$ & $\mathrm{n}$ & $\%$ \\
\hline Ampicilina & NT & NT & 5 & 100 & 1 & 100 & 2 & 100 & 2 & 100 \\
\hline Amicacina & 2 & 100 & 5 & 0 & 1 & 0 & 2 & 0 & 2 & 0 \\
\hline Amp+sub & 2 & 0 & 5 & 100 & 1 & 100 & 2 & 100 & 2 & 100 \\
\hline Cefazolina & NT & NT & NT & NT & 1 & 100 & 2 & 100 & NT & NT \\
\hline Cefepime & 2 & 100 & 5 & 100 & 1 & 100 & 2 & 0 & 2 & 100 \\
\hline Cefoxitina & NT & NT & 5 & 0 & 1 & 100 & 2 & 100 & 2 & 100 \\
\hline Ceftazidina & 2 & 100 & NT & NT & NT & NT & NT & NT & NT & NT \\
\hline Ceftriaxona & NT & NT & 5 & 80 & 1 & 100 & 2 & 100 & 2 & 100 \\
\hline Ciprofloxacino & 2 & 100 & 5 & 0 & 1 & 0 & 2 & 0 & 2 & 100 \\
\hline Ertapenem & NT & NT & 5 & 0 & 1 & 100 & 2 & 0 & 2 & 100 \\
\hline Gentamicina & 2 & 100 & 5 & 0 & 1 & 0 & 2 & 0 & 2 & 100 \\
\hline Imipinem & 2 & 100 & 5 & 0 & 1 & 0 & 2 & 0 & 2 & 0 \\
\hline Levofloxacino & 2 & 100 & NT & NT & NT & NT & NT & NT & 2 & 100 \\
\hline Meropenem & 2 & 100 & 5 & 0 & 1 & 0 & 2 & 0 & 2 & 100 \\
\hline Pipe+Tazo & 2 & 100 & 5 & 0 & 1 & 100 & 2 & 0 & 2 & 100 \\
\hline Smt+tmp & 2 & 100 & 5 & 100 & NT & NT & 2 & 0 & 2 & 100 \\
\hline Tigeciclina & NT & NT & 5 & 0 & 1 & 100 & 2 & 50 & 2 & 0 \\
\hline
\end{tabular}

Legenda: NT: não testado; n: número de isolados bacterianos; \%: percentual de resistência; pipe+tazo: piperacilina + tazobactam; smt+tmp: sulfametoxazol + trimetoprima; amp+sub: ampicilina + sulbactam. Fonte: Autores. 


\section{Discussão}

Os microrganismos mais prevalentes pertenceram ao grupo de bactérias gram positivas (59\%), enquanto as gram negativas corresponderam a 41\% das hemoculturas. Foi observado padrão semelhante em estudo realizado no Distrito Federal, onde houve $20,9 \%$ de hemoculturas com resultado positivo, sendo que os microrganismos mais prevalentes pertenceram ao grupo de bactérias gram positivas $(65,8 \%)$ seguidas por leveduras $(22,7 \%)$ e bactérias gram-negativas $(11,3 \%)$ (Monteiro et al., 2019); assim como foi observado predomínio de gram positivas $(65,2 \%)$ em estudo desenvolvido em hospital universitário de Santa Maria, no Sul do Brasil. O predomínio desse grupo em hemoculturas está relacionado com a colonização da microbiota normal do ser humano por essas bactérias, dessa forma, colonizando, também, os cateteres dos pacientes (Gohel et al., 2014).

Frequentemente um grupo de bactérias está relacionado a elevados índices de resistência hospitalar: ESKAPE (Enterococcus faecium, Staphylococcus aureus, Klebsiella pneumoniae, Acinetobacter baumannii, Pseudomonas aeruginosa, Enterobacter spp.) (Zhu et al., 2014). As bactérias isoladas nesse estudo condizem com este acrônimo. Foram encontrados altos índices de resistências pelas bactérias S. aureus, K. pneumoniae, A. baumannii e Enterobacter cloacae.

Dentre as bactérias gram-positivas, houve predomínio de $S$. coagulase negativa (76\%), seguido por S. aureus (18\%). Dessa forma, observa-se conformidade com o estudo realizado em Santa Maria, em que houve maior predomínio de $S$. epidermidis $(38,1 \%)$ (Foletto et al., 2019), bactéria inclusa no grupo dos $S$. coagulase negativa (SCN). Os SCN são os mais presentes na microbiota normal da pele e estão cada vez mais relacionados a importantes infecções como bacteremia e endocardite (Tufariello et al., 2020), sendo o S. epidermidis uma causa frequente de sepse, sobretudo em neonatos (Otto, 2017). Além disso, é frequentemente relacionado a infecções de dispositivos e próteses, sendo os imunocomprometidos considerados de risco para infecções dessa espécie (Tufariello et al., 2020).

Com relação aos microrganismos gram negativos, este estudo apresentou maior incidência da bactéria $E$. coli, seguida por A. baumannii, K. pneumoniae e K. aerogenes. Foram destaques também as bactérias $K$. pneumoniae (26,3\%), seguida por E. coli $(24,8 \%)$ em estudo realizado em Santa Maria (Foletto et al., 2019). Esses microrganismos fazem parte da microbiota intestinal humana, por isso, estão relacionadas frequentemente a infecções do trato geniturinário.

Em relação ao perfil de sensibilidade, as bactérias gram positivas foram sensíveis à daptomicina, linezolide e vancomicina. Rampelotto et al. também encontrou sensibilidade a essas drogas pelos microrganismos S. epidermidis, $S$. hominis, S. haemolyticus e S. aureus (Rampelotto et al., 2015).

Todas as bactérias gram negativas apresentaram sensibilidade à amicacina, exceto A. baumannii que apresentou resistência a todos os antimicrobianos testados: amicacina, cefepime, ceftazidina, ciprofloxacino, gentamicina, imipinem, levofloxacino, piperacilina+tazobactam, sulfametoxazol + tripetoprima e sensibilidade intermediária à ampicilina+sulbactam. Ainda em relação a A. baumannii, foram encontradas resistência a cefepime (81\%), ceftazidima (83,7\%), ceftriaxona $(82,6 \%)$, amicacina (67,4\%), imipenem (72,3\%) e para meropenem (75,5\%) em estudo realizado Cuiabá, Mato Grosso (Ricas et al., 2013).

A. baumannii tem se destacado quanto sua alta capacidade em adquirir mecanismos de resistência às diferentes classes de antimicrobianos, além de apresentar características como aptidão em sobreviver e se adaptar a condições adversas (Bastos et al., 2020). Dessa forma, o conjunto desses fatores se traduzem em elevadas taxas de morbimortalidade, sobretudo em pacientes críticos, tornando cada vez mais restrita as opções terapêuticas. A resistência aos carbapenêmicos pode ser explicada pela diminuição da permeabilidade das membranas externas, alteração na afinidade das proteínas ligadoras de penicilinas (PBPs) e, também, pela hiperexpressão de bombas de efluxo (Gusatti et al., 2009; Ribeiro et al., 2019). Entretanto, as principais formas de resistência aos carbapenêmicos são a expressão de metalo- $\beta$-lactamases (MBLs), as quais não são hidrolisadas por inibidores comerciais de serino $\beta$-lactamases, assim como a expressão de oxacilinases (OXA) (Walsh et al., 2005; Gusatti et al., 2009). As enzimas da família OXA possibilitam resistência a ampicilina e cefalotina e são descritas pela alta ação 
hidrolítica contra oxacilina e cloxacilina e por serem inibidas fracamente pelo ácido clavulânico (Brown \& Amyes, 2006). Sendo assim, a utilização da ampicilina+sulbactam surge como alternativa frente a disseminação de cepas multirresistentes a diferentes fármacos, principalmente aos carbapenêmicos.

Em relação ao perfil microbiológico, observou-se que houve resistência a ampicilina por grande parte das bactérias estudadas: S. coagulase negativa, S. aureus, E. coli, E. cloacae, K. aerogenes e K. pneumoniae. Essa realidade já foi relatada na literatura, chegando a apresentar $100 \%$ de resistência pelas bactérias gram negativas e gram positivas em trabalho realizado no Hospital Universitário de Santa Maria (HUSM) (Rampelotto et al., 2015).

Considerando as cepas gram positivas, sabe-se que as espécies $S$. aureus e Enterococcus spp. possuem importantes taxas de resistência aos antibióticos (Araujo et al., 2017). Em relação ao S. aureus, foi observado apenas resistência a ampicilina e penicilina, assim como no estudo realizado em hospital público do estado de Tocantins, onde foi iniciado o uso de meticilina/oxacilina após os testes demonstrarem resistência às penicilinas (Araujo et al., 2017). Entretanto, observou-se ainda no estudo em Tocantins que pouco tempo após o uso dessa antibioticoterapia, as cepas de $S$. aureus resistentes à meticilina (MRS) começaram a ser isoladas (Araujo et al., 2017). A cepa de E. faecalis isolada neste trabalho apresentou resistência apenas à ceftarolina, contrariando as altas resistências encontradas em outras pesquisas (García et al., 2018).

Entretanto, o uso cada vez mais frequente da vancomicina para o combate ao Enterecoccus spp. e Staphylococcus spp. têm reduzido a sensibilidade a esse antibiótico. Para Chang et al., essa resistência teria sido adquirida por meio da transferência de um plasmídeo contendo o transposon do gene vanA, Tn1546, de um E. faecalis resistente à vancomicina para o Staphylococcus aureus resistente a meticilina (MRSA), que já possuía um plasmídeo codificando resistência à gentamicina e produção de Betalactamase (Weigel et al., 2003). Por isso, tem sido recomendado o uso de fármacos como linezolide em substituição do uso desnecessário e abusivo da vancomicina, além da adoção de medidas de vigilância epidemiológica nos serviços de saúde (Mimica \& Berezin, 2018).

Em relação às cepas gram negativas, a bactéria $E$. coli foi a mais isolada (42\%), assim como em estudo realizado por Santo et tal., onde o microrganismo mais frequente em amostras de pacientes internados foi a E. coli, correspondendo a $30 \%$ dos casos. A E. coli, neste estudo, apresentou resistência à ampicilina, ampicilina+sulbactam, cefepime, ceftriaxona e sulfametoxazol+trimetoprima e sensibilidade intermediária a ciprofloxacino, sendo a classe das quinolonas uma das mais utilizadas para tratamento de infecções urinárias (Salzani et al., 2019); devido, sobretudo, ao aumento da resistência ao sulfametoxazol + trimetoprim em todo o mundo (Critchley et al., 2019).

A resistência por parte da E. coli aos betalactâmicos está relacionada essencialmente pela produção de betalactamases de espectro estendido (ESBLs) do tipo TEM ou SHV, também conhecidas como ceftazidimases, codificadas por plasmídeos (Bastos et al., 2020). Estas enzimas possuem a capacidade de hidrolisar penicilinas e cefalosporinas, com maior atividade hidrolítica para a ceftazidima (entre as cefalosporinas de largo espectro) e possuem a capacidade de ser inibidas pelo ácido clavulânico (Bastos et al., 2020). Além disso, foi descoberto um novo grupo de enzimas, o CTX-M, betalactamases de espectro estendido (Rivera-Jacinto et al., 2015), que tem se tornado cada vez mais frequente em ambientes hospitalares.

A Klebsiella spp. foi isolada em $33 \%$ das hemoculturas positivas para gram negativos, sendo metade dos casos de $K$. aerogenes e a outra de K. pneumoniae. A resistência da Klebsiella spp. está relacionada ao uso inadequado de antimicrobianos e a produção de beta-lactamases tipo AmpC e de carbapenemases, como as metalo-betalactamases (MBL) e carbapenemases do tipo KPC (Bastos et al., 2020; Marchaim et al., 2008). Grande parte das infecções associadas à K. pneumoniae, produtora da enzima KPC, ocorre em pacientes imunodeprimidos hospitalizados e/ou com dispositivos invasivos, sendo assim, a prevenção é a principal arma utilizada no combate desta bactéria (Marchaim et al., 2008). Neste estudo, a K. pneumoniae apenas apresentou sensibilidade à amicacina e sensibilidade intermediária à tigeciclina, demonstrando a elevada taxa de resistência aos demais antibióticos testados. Em pesquisa realizada em Minas Gerais, 36\% dos casos de infecção foram por K. pneumoniae 
produtora de Beta-lactamases de Espectro Estendido (Extended Spectrum Beta-lactamases-ESBL) e 28\% foram de $K$. pneumoniae produtora de carbapenemase (KPC) (Muniz et al., 2019; Ribeiro et al., 2019). Dessa forma, fica claro que a elevada resistência de suas cepas é um problema de saúde pública e prevê que medidas de controle e vigilância sejam tomadas.

\section{Conclusão}

Houve o predomínio das bactérias gram positivas nas hemoculturas do Hospital Universitário e aproximadamente 55\% das bactérias foram Staphylococcus spp, sendo que todas essas apresentaram resistência a ampicilina e penicilina. Além disso, a resistência por parte do K. pneumoniae e A. baumannii aos carbapenêmicos e às cefalosporinas nas hemoculturas estudas são preocupantes, visto que as elevadas taxas de mortalidade estão associadas às infecções de corrente sanguínea (Machado et al., 2017).

Sendo assim, estudos como este possibilitam, através do trabalho conjunto com a CCIH, o direcionamento adequado da instituição na construção de protocolos de antibioticoterapia empírica, assim como a elaboração e implementação de medidas preventivas e de controle das infecções, visando diminuir as taxas de morbimortalidade, os custos em saúde e o tempo de internação.

Pesquisas futuras a respeito do perfil clínico dos pacientes acometidos pelas IRAS na instituição podem corroborar para o conhecimento epidemiológico e microbiológico encontrado de modo a fundamentar melhores protocolos de controle às infecções.

\section{Referências}

Agência Nacional de Vigilância Sanitária. (2017). Medidas de Prevenção de Infecção Relacionada à Assistência à Saúde.

Araujo, M. Q., Poletto, K. Q., \& Bessa, N. G. (2017). Perfil de resistência bacteriana em fômites de UTI em hospital público do Estado do Tocantins. Revista Cereus, 9(2), 126-141.

Bastos, I. D. M., Bastos, B. D. M., Silva, C. F., Silva, K. S. B., \& Naue, C. R. (2020). Perfil bacteriano de amostras microbiológicas de pacientes internados na Clínica Cirúrgica de um Hospital Universitário de Pernambuco. VITTALLE-Revista de Ciências da Saúde, 32(1), $108-121$.

Brown, S., \& Amyes, S. (2006). OXA $\beta$-lactamases in Acinetobacter: The story so far. Journal of Antimicrobial Chemotherapy, 57(1), 1-3.

Center for Disease Control and Prevention. (2019). Healthcare-associated infections. https://www.cdc.gov/hai/index.html

Critchley, I. A., Cotroneo, N., Pucci, M. J., \& Mendes, R. (2019). The burden of antimicrobial resistance among urinary tract isolates of Escherichia coli in the United States in 2017. PLOS ONE, 14(12), e0220265.

dos Santos, R. P., Mariano, L. R., da Silva Takahashi, L., \& de Fatima Erdmann, M. (2014). Prevalência de infecção hospitalar em unidade de terapia intensiva - Um estudo retrospectivo. Revista de Enfermagem da UFSM, 4(2), 410-418.

Foletto, V. S., Bottega, A., Serafin, M. B., Rosa, T. F. da, Mainardi, A., Franco, L. N., \& Hörner, R. (2019). Prevalência e perfil de resistência aos antimicrobianos de hemoculturas em hospital universitário. Saúde (Santa Maria), 45(3), Article 3

Freitas, R. B., Santiago, M. T., Bahia, C. P., Pereira, L. P., Mello, C. M. V. de, Nogueira, A. C. R., Dias, A. de P., Capaverde, M. R. C., Ferrari, C. V., \& Antoniol, T. (2017). Aspectos relevantes da sepse. Revista Científica UNIFAGOC - Saúde, 1(2), $25-32$.

García, J. L. A., Flores, A. M. E., Barbosa, P. A., \& Cortina, J. H. M. (2018). Susceptibilidad antimicrobiana de Enterococcus faecalis y faecium en un hospital de tercer nivel. Revista Latinoamericana de Infectología Pediátrica, 31(2), 56-61.

Gohel, K., Jojera, A., Soni, S., Gang, S., Sabnis, R., \& Desai, M. (2014). Bacteriological Profile and Drug Resistance Patterns of Blood Culture Isolates in a Tertiary Care Nephrourology Teaching Institute. BioMed Research International, 2014, 153-747.

Gomes, A. A. G., Silva, M. R. da, Garcês, T. C. de C. S., Pinto, A. S. B., Andrade, S. M. O. de, Saraiva, E. R., Brito, S. M. S., Gadelha, D. dos S. G., \& Andrade, A. R. O. de. (2020). Infecções relacionadas à assistência em saúde em unidades de terapia intensiva no Brasil. Revista Eletrônica Acervo Saúde, 12(11), e4665-e4665.

Gusatti, C. de S., Ferreira, A. E., Fuentefria, D. B., \& Corção, G. (2009). Resistência a $\beta$-lactâmicos em Acinetobacter spp isolados de efluente hospitalar no sul do Brasil. Revista da Sociedade Brasileira de Medicina Tropical, 42(2), 183-187

Machado, F. R., Cavalcanti, A. B., Bozza, F. A., Ferreira, E. M., Carrara, F. S. A., Sousa, J. L., ... \& Melo, R. S. (2017). The epidemiology of sepsis in Brazilian intensive care units (the Sepsis PREvalence Assessment Database, SPREAD): an observational study. The Lancet Infectious Diseases, 17(11), 11801189. 
Marchaim, D., Navon-Venezia, S., Schwaber, M. J., \& Carmeli, Y. (2008). Isolation of imipenem-resistant Enterobacter species: emergence of KPC-2 carbapenemase, molecular characterization, epidemiology, and outcomes. Antimicrobial agents and chemotherapy, 52(4), 1413-1418.

Miller, J. M., Binnicker, M. J., Campbell, S., Carroll, K. C., Chapin, K. C., Gilligan, P. H., ... \& Yao, J. D. (2018). A guide to utilization of the microbiology laboratory for diagnosis of infectious diseases: 2018 update by the Infectious Diseases Society of America and the American Society for Microbiology. Clinical Infectious Diseases, 67(6), e1-e94.

Mimica, M. J., \& Berezin, E. N. (2018). Staphylococcus aureus resistente à vancomicina: um problema emergente. Arquivos médicos dos hospitais e da Faculdade de Ciências Médicas da Santa Casa de São Paulo, 51(2), 52-56.

Monteiro, M. M., Souza, T. M. D., \& Mendes, T. D. P. L. (2019). Perfil microbiológico de hemoculturas em uma Unidade de Terapia Intensiva Neonatal do Distrito Federal. Comunicação em Ciências da Saúde.

Muniz, J. J., Silva, A. G., Rosa, A. D. F. N., de Melo, F. A., \& Mattozo, J. M. A. (2019). Resistência aos antibióticos utilizados para tratamento de infecções por Klebsiella pneumoniae em um hospital. Revista de Ciências da Saúde Básica e Aplicada, 2, 3-10.

Oplustil, C. (2010). Procedimentos Básicos Em Microbiologia Clinica (3a edição). SARVIER EDITORA DE LIVROS MEDICOS LTDA.

Otto, M. (2017). Staphylococcus epidermidis: a major player in bacterial sepsis?. Future Medicine. 1031-1033.

Pereira, A.S. et al. (2018). Metodologia da pesquisa científica. [e-book]. Santa Maria. Ed. UAB/NTE/UFSM. Disponível em: https://repositorio.ufsm.br/bitstream/handle/1/15824/Lic_Computacao_Metodologia-Pesquisa-Cientifica.pdf?sequence=1 .

Rampelotto, R. F., Hörner, R., Martini, R., Nunes, M. S., Garzon, L. R., Dos Santos, S. O., \& Bottega, A. (2015). Análisis de la susceptibilidad de los antimicrobianos frente a bacterias aisladas de bacteriemias en un hospital universitario. Revista Cubana de Farmacia, 49(1), 61-69.

Ribeiro, T. D. S., Ribeiro, R. A. A. D. S., Batista, K. S., Aquino, S. R. D., \& Naue, C. R. (2019). Ocorrência e perfil bacteriano de culturas coletadas em pacientes internados na unidade de terapia intensiva em um hospital terciário. HU rev, 122-133.

Ricas, R. V., Marques, T. C., \& Yamamoto, A. C. A. (2013). Perfil de resistência de Acinetobacter baumannii a antimicrobianos em um hospital universitário de Cuiabá-MT. Infarma Ciências Farmacêuticas, 25(4), 178-181.

Rivera-Jacinto, M., Rodríguez-Ulloa, C., Flores Clavo, R., Serquén López, L., \& Arce Gil, Z. (2015). Betalactamasas de espectro extendido tipo TEM y CTX$\mathrm{M}$ en Klebsiella spp y Escherichia coli aisladas de superficies de ambientes hospitalarios. Revista Peruana de Medicina Experimental y Salud Pública, 32, 752755.

Rodrigues, T. S., dos Santos, A. M. R., Lima, P. C., Moura, M. E. B., Goiano, P. D. D. O. L., \& da Silva Fontinele, D. R. (2018). Resistência bacteriana a antibióticos na Unidade de Terapia Intensiva: revisão integrativa. Revista Prevenção de Infecção e Saúde, 4.

Salzani, M. G. B., Maior, F. N. S., de Menezes, C. C., Santos, P., Lima, I. O., da Silva, S. O. P., \& de Sousa Mendes, R. (2019). Infecções urinárias: buscando evidenciar as drogas mais usadas no tratamento dessas patologias. Temas em Saúde. 19(3).

Secretaria Estadual de Saúde de Pernambuco. (2020). http://portal.saude.pe.gov.br/unidades-de-saude-e-servicos/secretaria-executiva-de-coordenacaogeral/viii-geres

Tufariello, J. M., Lowy, F. D., \& Kaplan, S. L. (2020). Infection due to coagulase-negative staphylococci: Epidemiology, microbiology, and pathogenesis. UpToDate. Waltham, MA.

Walsh, T. R., Toleman, M. A., Poirel, L., \& Nordmann, P. (2005). Metallo- $\beta$-lactamases: the quiet before the storm?. Clinical microbiology reviews, 18(2), 306-325.

Weigel, L. M., Clewell, D. B., Gill, S. R., Clark, N. C., McDougal, L. K., Flannagan, S. E., ... \& Tenover, F. C. (2003). Genetic analysis of a high-level vancomycin-resistant isolate of Staphylococcus aureus. Science, 302(5650), 1569-1571.

World Health Organization. (2019) No Time to Wait: Securing the future from drug-resistant infections. http://www.who.int/antimicrobialresistance/interagency-coordination-group/final-report/en/

Zhu, H., Swierstra, J., Wu, C., Girard, G., Choi, Y. H., van Wamel, W., ... \& van Wezel, G. P. (2014). Eliciting antibiotics active against the ESKAPE pathogens in a collection of actinomycetes isolated from mountain soils. Microbiology, 160(8), 1714-1725. 